\title{
Review Article \\ Hypoxia-Inducible Factor-1: A Potential Target to Treat Acute Lung Injury
}

\author{
Yang Liu, ${ }^{1}$ Du Xiang, ${ }^{1}$ Hengcheng Zhang, ${ }^{2}$ Hanlin Yao, ${ }^{1}$ and Yanfeng Wang ${ }^{1}{ }^{1}$ \\ ${ }^{1}$ Zhongnan Hospital of Wuhan University, Institute of Hepatobiliary Diseases of Wuhan University, Transplant Center of \\ Wuhan University, Wuhan 430071, China \\ ${ }^{2}$ Transplantation Research Center, Renal Division, Brigham and Women's Hospital, Harvard Medical School, Boston, \\ 02115 MA, USA
}

Correspondence should be addressed to Yanfeng Wang; yanfengwang@whu.edu.cn

Received 3 September 2020; Revised 29 October 2020; Accepted 4 November 2020; Published 17 November 2020

Academic Editor: Emiliano Barreto

Copyright ( 2020 Yang Liu et al. This is an open access article distributed under the Creative Commons Attribution License, which permits unrestricted use, distribution, and reproduction in any medium, provided the original work is properly cited.

\begin{abstract}
Acute lung injury (ALI) is an acute hypoxic respiratory insufficiency caused by various intra- and extrapulmonary injury factors. Presently, excessive inflammation in the lung and the apoptosis of alveolar epithelial cells are considered to be the key factors in the pathogenesis of ALI. Hypoxia-inducible factor-1 (HIF-1) is an oxygen-dependent conversion activator that is closely related to the activity of reactive oxygen species (ROS). HIF-1 has been shown to play an important role in ALI and can be used as a potential therapeutic target for ALI. This manuscript will introduce the progress of HIF-1 in ALI and explore the feasibility of applying inhibitors of HIF-1 to ALI, which brings hope for the treatment of ALI.
\end{abstract}

\section{Introduction}

Acute lung injury (ALI) refers to increased alveolar-capillary permeability caused by severe noncardiogenic factors such as severe infection, shock, and burns, resulting in diffuse pulmonary interstitial and parenchymal edema [1]. The clinical manifestations of ALI are progressive hypoxemia or acute respiratory distress syndrome (ARDS) and can even progress to fatal respiratory failure $[2,3]$. ALI/ARDS is a disease that endangers human health worldwide. Although research on the pathogenesis and molecular mechanism of ALI/ARDS has made remarkable progress, its morbidity and fatality rate are still high. Recent studies have reported that the incidence of ALI/ARDS is $1 \% \sim 4 \%$, the case fatality rate is $22 \% \sim 65 \%$, and the case fatality rate in the pediatric population is approximately $24 \%$; thus, it is urgent to find an effective treatment for ALI [4]. In the pathogenesis of ALI/ARDS, various factors stimulate the production and accumulation of a large number of inflammatory cells (neutrophils, mononuclear macrophages, etc.) in the lung. At the same time, inflammatory cells activate and release proinflammatory factors such as reactive oxygen species (ROS), tumor necrosis factor $\alpha$ (TNF- $\alpha$ ), interleukins (ILs), and elastase, which promote the deterioration of the inflammatory response $[5,6]$. ROS can destroy pulmonary microvascular endothelial cells and epithelial cells in different ways, increase pulmonary vascular permeability, and lead to the formation of pulmonary edema. In addition, ROS can interact with inflammatory factors and promote the expression of inflammatory factorrelated proteins, resulting in an inflammatory cascade [7, 8]. Hypoxia-inducible factor-1 (HIF-1) is an oxygendependent transcriptional activator that was first discovered in 1992 [9]. HIF-1 is widely expressed in tissue during hypoxia, and it plays an important pathophysiological role in maintaining oxygen homeostasis in the body by regulating the expression of a series of genes related to the adaptation to hypoxia [9]. HIF-1 is also an important inflammatory regulator involved in the regulation of acute and chronic inflammation $[10,11]$. Interestingly, under hypoxic conditions, ROS released from the mitochondrial electron transport chain can participate in the regulation of HIF-1 activity [12]. Previous studies have reported that HIF-1 plays an important role in ALI and participates in inflammation, apoptosis, and pulmonary fibrosis by regulating corresponding 
target genes, but its specific mechanism is not very clear. Our review focuses on the interaction between HIF-1 and ROS and the role of HIF-1 in the pathogenesis of ALI and the progress in the treatment of ALI with HIF-1 inhibitors.

\section{HIF-1}

2.1. The Structure of HIF-1. HIF-1 is a heterodimer composed of the functional subunit HIF- $1 \alpha(120 \mathrm{kD})$ and the structural subunit HIF-1 $\beta(91 \sim 94 \mathrm{kD})$ [13]. The human HIF- $1 \alpha$ gene is located on chromosome 14 (14 q21-24) and has a length of $3720 \mathrm{bp}$, and the protein it encodes is an 826-amino acid polypeptide. The length of the human HIF-1 $\beta$ gene is $2604 \mathrm{bp}$, and the protein it encodes is a 774- or 789-amino acid polypeptide [13]. HIF- $1 \alpha$, a regulatory and active subunit, is a unique subunit structure of HIF-1. HIF- $1 \beta$, also known as aryl hydrocarbon receptor nuclear translocator (ARNT), is a subunit of an aromatic hydrocarbon receptor complex that can form dimers with proteins. The $\alpha$ and $\beta$ subunits have the following structure: (1) the aminoterminal half of each subunit contains a basic helix-loophelix (bHLH) that defines a large superfamily of dimeric eukaryotic transcription factors in which the HLH domain mediates dimerization and the basic domain contacts DNA; (2) the Per-aryl hydrocarbon receptor nuclear translocatorSim (Per-ARNT-Sim; PAS) domain contributes to the formation of protein dimers; and (3) the carboxyl terminus of each subunit contains a transcription activation domain (TAD), which can bind to the transcription initiation complex to regulate gene transcription [13] (Figure 1). TAD in the HIF- $1 \alpha$ structure contains TAD-N and TAD-C, which can participate in transcriptional activation. There is an inhibitory domain (ID) between TAD-N and TAD-C, which can significantly reduce the activity of TAD under normoxia.

2.2. The Regulation in HIF-1 Expression. The $\alpha$ subunit is a unique regulatory and active subunit of HIF-1 [14]. The stability and transcriptional activity of the HIF-1 protein are both regulated by intracellular oxygen concentration $[15,16]$. Therefore, the physiological activity of HIF-1 mainly depends on the activity and expression of the HIF- $1 \alpha$ subunit [16]. The $\beta$ subunit is shared by many transcription factors, and it can be constitutively expressed in the nucleus without being regulated by the oxygen concentration. The function of the $\beta$ subunit may be related to maintaining the structural stability of HIF-1 and the active conformational changes caused by dimerization [17]. HIF- $1 \alpha$ must form a heterodimer with HIF- $1 \beta$ to become active HIF-1 [17]. HIF-1 is a core transcription factor that induces hypoxia genes and repairs the internal microenvironment of cells. HIF- $1 \alpha$ is an oxygen regulatory protein that is very sensitive to the concentration of oxygen and is called the "master switch of hypoxia gene expression" [18]. Under normal oxygen conditions, the oxygen-dependent degradation domain (ODDD) on the HIF-1 gene is hydroxylated by prolyl hydroxylase (PHD), binds with ubiquitin E3 ligase (von Hippel-Lindau, pVHL), and is ultimately degraded through the protein ubiquitination hydrolysis system $[19,20]$. When the cell is in a hypoxic state or the function of pVHL is lost, the mitochondrial elec- tron transport chain is also inhibited. In addition, the accumulation of ROS and various metabolites such as lactic acid and pyruvate also inhibits $\mathrm{PHD}$ and reduces the degradation of HIF-1 and stabilizes its expression [21, 22] (Figure 2). HIF- $1 \alpha$ accumulates and is transported to the nucleus to forming the HIF-1 complex following binding with HIF- $1 \beta$ [23]. In addition, HIF- $1 \alpha$ acts as a transcription factor in conjunction with the hypoxia reaction element (HRE) to further activate the transcription of multiple downstream target genes, such as vascular endothelial cell growth factor (VEGF), erythropoietin (EPO), and induced nitric oxide synthase (iNOS), which in turn triggers a series of oxygen-resistant adaptive responses in tissues and cells [24].

2.3. The Downstream Target Genes and Functions of HIF-1. The target genes regulated by HIF-1 all contain HREs. After HIF- $1 \alpha$ specifically recognizes and binds to the core HRE sequence $\left(5^{\prime}\right.$-RCGTG- $\left.3^{\prime}\right)$, it exerts a transcriptional activation effect and activates the transcription of target genes [25]. These activated genes are as follows: (1) angiogenesis-related genes such as VEGF and its receptor [26]; (2) various enzymes involved in glucose metabolism, energy metabolism, and cell proliferation such as adenosine kinase (AK), pyruvate kinase M2 (PKM2), phosphoglycerate kinase 1 (PGK1), hexokinase II, pyruvate dehydrogenase kinase $(\mathrm{PDK})$, lactate dehydrogenase $(\mathrm{LDH})$, glucose transporters (GLUT), glyceraldehyde-3-phosphate dehydrogenase (GAPDH), and transforming growth factor (TGF- $\beta$ ) [27-31]; (3) red blood cell metabolism- and iron metabolismrelated genes such as erythropoietin (EPO), transferrin, and transferrin receptor-1 (TfR1) [32, 33]; and (4) heme oxygenase (HO) and iNOS $[34,35]$. HIF- $1 \alpha$ regulates angiogenesis, energy metabolism, red blood cell production, cell proliferation and survival, vascular remodeling, and the vasomotor response by regulating the expression of its downstream target genes so that hypoxic tissues and cells can maintain oxygen homeostasis to tolerate hypoxia [26-30, 36-38].

\section{HIF-1 and ROS}

3.1. ROS. ROS are unstable compounds containing highly reactive oxygen molecules that are produced by redox reactions [39]. ROS include oxygen-containing free radicals (superoxide anion free radicals, hydroxyl free radicals, etc.), nonradical derivatives of oxygen, hydroperoxides, and lipid peroxides [40-43]. Among them, oxygen-free radicals mainly refer to superoxide anion radicals (O2•-), hydroxyl radicals $(\bullet \mathrm{OH})$, peroxides $\left(\mathrm{RO}_{2}\right)$, and oxygen organic-free radicals (RO•) [44-46]. ROS are produced and exert their biological effects in mitochondria. ROS produced by mitochondria can be released into the cytoplasm through specific mitochondrial ion channels/transporters, such as the mitochondrial permeability transition pore (mPTP) [47]. ROS can also be generated by extramitochondrial enzymes such as reduced nicotinamide adenine dinucleotide phosphate oxidase (NOX), lipoxygenase, xanthine oxidase, myeloperoxidase, and cytochrome P450 cyclooxygenase [48-51]. There is a complex antioxidant system in the body that can produce and remove ROS in a dynamic balance under normal 


\begin{tabular}{|c|c|c|c|c|c|}
\hline HIF- $1 \alpha$ & bHLH & PAS & TAD-N & ID & TAD-C \\
\hline HIF- $1 \beta$ & bHLH & PAS & & & \\
\hline
\end{tabular}

Figure 1: The structures of HIF-1 $\alpha$ and HIF-1 $\beta$. bHLH: helix-loop-helix; PAS: Per-aryl hydrocarbon receptor nuclear translocator-Sim; TAD: transcription activation domain; ID: inhibitory domain.

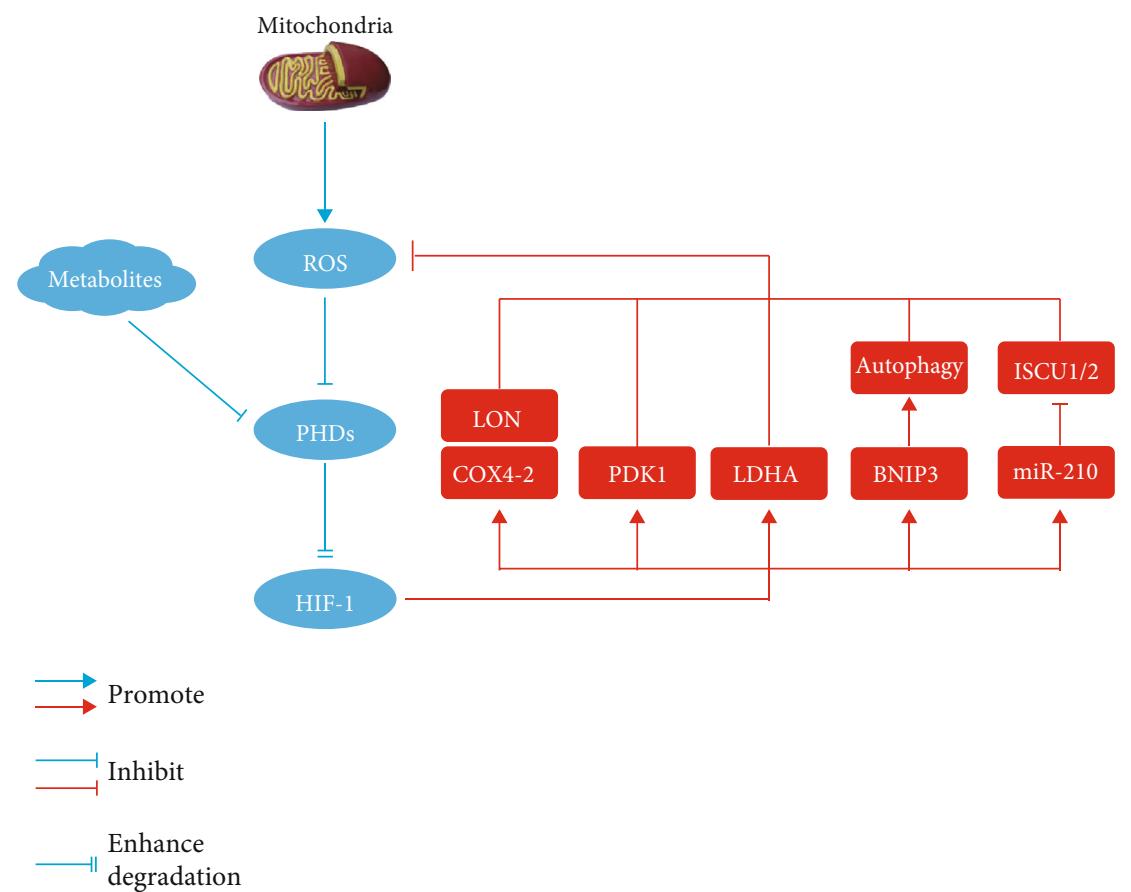

FIgURE 2: The interplay between HIF-1 and ROS under hypoxic condition. PHD: prolyl hydroxylase; LON: mitochondrial ATP dependent matrix protease; COX-4: cytochrome c oxidase IV-2; PDK-1: pyruvate dehydrogenase (PDH) kinase 1; LDHA: lactate dehydrogenase A; BNIP3: BCL2 and adenovirus E1B $19 \mathrm{kDa}$-interacting protein 3; ISCU1/2: iron-sulfur cluster assembly protein.

circumstances to avoid causing damage to the body [52]. In some specific cases, the accumulation of ROS in cells increases, which can cause excessive oxidation of proteins, lipids and, DNA, resulting in varying degrees of cell damage [53]. ROS bind to proteins to produce carbonyl derivatives, which change the tertiary structure of proteins, resulting in partial or full unfolding, and easily form protein-protein crosslinks, resulting in protein denaturation or the loss of enzymatic activity [54]. The main physiological functions of ROS in the body include participation in the immune response and biological aging process, as well as the regulation of some signaling pathways $[55,56]$.

Excessive production of ROS is key to the development of ALI, which can affect the activation of lung inflammatory cells and the release of inflammatory mediators and can also damage the alveolar-vascular endothelial cell barrier structure, resulting in a decrease in barrier stability [57]. Under physiological conditions, the elimination of ROS depends on the effectiveness of antioxidant substances in the body to maintain a dynamic balance. However, under pathological conditions, such as acute inflammation, the amount of ROS produced far exceeds the scavenging capacity of the antioxidant system. Excessive ROS accumulate in the body and destroy the structure and function of tissues and organs and cause metabolic disorders through oxidative stress and inflammation cascade amplification [58].

3.2. The Impact of ROS on ALI. ROS oxidize or damage proteins, lipids, and DNA, thereby directly or indirectly inducing protein denaturation and lipid peroxidation. If the excessive accumulation of ROS exceeds the elimination ability of the body's antioxidant system, cell and tissue damage occur. The oxidative effect of ROS mediates lung injury $[59,60]$ through the following mechanisms: (1) ROS oxidize phospholipids on the surface of cell membranes, causing fatty acid chain breaks, membrane structure disorders, and decreased fluidity and permeability, resulting in lung dysfunction. (2) ROS oxidize lipid molecules to produce a large number of vasoactive substances and proinflammatory molecules, such as promoting the formation of a large number of thromboxanes, thereby increasing the degree of pulmonary vascular tension and inflammation. (3) ROS oxidize the amino acids in the protein-peptide chain, destroy the basic molecular structure of the protein, and change the activity and function of the protein. ROS antioxidant enzymes cause oxidation and antioxidation imbalance in the body. (4) ROS activate 
transcription factors through oxidation, such as nuclear factor kappa-B (NF- $\kappa \mathrm{B})$ and protease activating factor-1 (Apaf-1), to upregulate inflammation-targeting proteins (intercellular adhesion molecules, cyclooxygenase-2, etc.), thereby promoting inflammation [61]. (5) ROS can oxidize DNA and cause DNA base deletions, point mutations and strand breaks, causing cell damage and even cell death. Increased ROS production can destroy the microstructure of cells through self-oxidation, which can cause structural or functional damage to pulmonary vascular endothelial cells, epithelial cells, and smooth muscle cells, resulting in dysfunction of the alveolar-vascular endothelial barrier and vasomotor function, thereby promoting the progression of ALI.

3.3. The Interaction of ROS and HIF-1. Mitochondria are the main organelles associated with cellular oxygen consumption and the main site of ROS production. HIF-1 is a transcription factor that regulates hypoxia adaptation. Under hypoxic condition, ROS are involved in the regulation of HIF-1 activity. A hypoxic environment promotes the production of ROS in mitochondria, and a large amount of ROS can promote the stability of the HIF-1 protein under hypoxic conditions [62]. In addition, hypoxia may initially promote oxidative stress through mitochondrial ROS production. The increased ROS can upregulate HIF-1, and activated HIF- $1 \alpha$ can cause persistently high levels of oxidative stress by promoting the production of oxidative products or inhibiting the antioxidant effect [63-66]. Interestingly, HIF-1 also has the ability to inhibit oxidative phosphorylation and ROS generation [67], which indicates that a negative feedback loop in which ROS-mediated regulation of HIF-1 plays a key role. HIF-1 can prevent the excessive production of mitochondrial ROS under hypoxic conditions rather than promote oxidative stress. Studies have shown that the expression of HIF-1 in cells in vivo and in vitro can prevent excessive accumulation of ROS and inhibit cell apoptosis [68-71]. Therefore, maintaining a balance between HIF-1 and ROS is essential. The possible mechanism by which HIF-1 reduces ROS generation under hypoxia [71] is as follows: (1) Cells express the COX41 (cytochrome $c$ oxidase $\mathrm{IV}-1$ ) regulatory subunit of cytochrome $c$ oxidase (ETC complex IV) under aerobic conditions but switch to the COX4-2 (cytochrome c oxidase IV-2) subunit under hypoxic conditions. HIF-1 activates transcription of the genes encoding COX4-2 and LON (a mitochondrial protease that is required for the degradation of COX4-1). Under conditions of chronic hypoxia, ETC complex IV can also become a source of increased ROS production if the COX4 subunit switch does not occur [72]. (2) HIF-1 activates the gene encoding pyruvate dehydrogenase $(\mathrm{PDH})$ kinase 1 (PDK1), which shunts pyruvate away from the mitochondria [68]. PDK1 and LDHA (lactate dehydrogenase A) cooperate to decrease ETC flux and offset the reduced $f$ electron transport efficiency under hypoxic conditions to reduce the production of ROS [73]. (3) HIF-1 activates the gene encoding BNIP3 (BCL2 and adenovirus E1B $19 \mathrm{kDa}$-interacting protein 3 ), which triggers selective mitochondrial autophagy [74]. (4) MicroRNA-210 is induced, which blocks iron-sulfur cluster assembly proteins
(ISCU1/2) that are required for oxidative phosphorylation [75] (Figure 2).

\section{HIF-1 and Inflammation}

The inflammatory response requires the interaction of a series of cytokines, and HIF- $1 \alpha$ is an important factor associated with gene regulation during the inflammatory response. There is a positive feedback proinflammatory effect in ALI, and a large number of inflammatory factors upregulate HIF-1. Increased HIF-1 stimulates the release of inflammatory factors, amplifies the inflammatory response, and exacerbates lung injury [76]. Li et al. [77] showed that intracellular succinate induced angiogenesis through HIF- $1 \alpha$ induction, which is related to the activation of the VEGF gene. HIF- $1 \alpha$ accumulates under hypoxic conditions and can bind with the VEGF gene promoter to induce VEGF expression [77]. In allergic airway diseases, VEGF is an effective stimulator of inflammation and can promote airway remodeling and physiological dysfunction [78, 79]. In a mouse model of allergic airway disease caused by the inhalation of ovalbumin (OVA), the expression levels of HIF-1 $\alpha$ and VEGF increased, and the production of inflammatory mediators, such as IL-4, IL-5, and IL-13, significantly increased, airway hyperresponsiveness and pulmonary vascular permeability increased, which confirmed that the inhibition of HIF- $1 \alpha$ could reduce antigen-induced airway inflammation and hyperresponsiveness by regulating VEGFmediated vascular leakage [80]. Under normoxic conditions, interleukin-1 $\beta$ (IL-1 $\beta$ ), IL-6, TNF- $\alpha$, and other cytokines are upregulated by HIF-1. Under hypoxia, cytokines can increase HIF-1 activity [81].

The NF- $\kappa$ B family controls multiple processes, including immunity, inflammation, tumor cell proliferation, and nervous system function [82]. Mo et al. [83] showed that the expression of NF- $\kappa \mathrm{B}$ in alveolar of ALI/ARDS patients was abnormally increased, and the activation of NF- $\kappa \mathrm{B}$ may contribute to the increased expression of a variety of cytokines in the lung. Chen et al. [84] confirmed that NF- $\kappa$ B was abnormally upregulated in the alveolar cells of ALI patients and regulated the production of a large number of gene products with NF- $\kappa$ B sites, such as IL- $1 \beta$, IL- 6 , and TNF- $\alpha$. The interaction of various cytokines and inflammatory factors initiates the inflammatory cascade, which ultimately leads to ALI [85, 86]. In addition, HIF- $1 \alpha$ can act on various adenylate receptors, thereby alleviating lung injury $[87,88]$. For example, HIF- $1 \alpha$ can effectively reduce the severity of ALI and prolong patient survival by regulating A2BAR (adenosine receptor A2b) [89].

\section{HIF-1 and Apoptosis of Alveolar Epithelial Cells}

Alveolar type II (AT-II) cells are also known as granular alveolar cells. AT-II cell apoptosis occurs in the early stage of ALI, leads to the loss of a large number of alveolar epithelial cells, and ultimately promotes the progression of ARDS [90]. In the progression of ALI, HIF- $1 \alpha$ can increase glucose metabolism in tracheal epithelial cells, thereby increasing 
lung ventilation and improving pulmonary edema and respiratory distress. However, more studies have confirmed that HIF- $1 \alpha$ promotes AT-II cell apoptosis. This effect may be related to different signaling pathways regulated by HIF- $1 \alpha$. Krick et al. [91] found that hypoxia suppressed alveolar epithelial cell proliferation and enhanced AT-II cell apoptosis through activation of the HIF- $1 \alpha / \mathrm{HRE}$ axis and a mechanism that involves Bnip3L; thus, targeting HIF- $1 \alpha$ may represent a new strategy to attenuate the degree of acute lung injury. He et al. [92] suggested that hypoxia-induced apoptosis in AT-II cells could be alleviated by inhibiting the HIF- $1 \alpha$-HRE axis.

\section{HIF-1 and Pulmonary Fibrosis}

Pulmonary fibrosis (PF) after ALI is a process in which lung inflammation leads to persistent alveolar damage, the production of extracellular matrix, repeated cell destruction, repair, and reconstruction, and excessive collagen deposition. $\mathrm{PF}$ is also an excessive repair response after tissue damage [93]. The pathological changes in ALI/ARDS are progressive. In the early stage of ALI/ARDS (within 7 days), the pathological changes in the lung tissue are dominated by exudation. After 7 days, ALI may develop into a fibrotic stage and generally develops into a fibrotic stage after 3 weeks [94]. Previous studies have shown that fibroblast proliferation and collagen secretion can be enhanced in the early stage of ALI. In other words, there are obvious fibrotic changes in the early stage of ALI [95, 96]. Alveolar epithelial cells (AECs) adhere tightly to adjacent cells or the basement membrane to protect the lungs from injury and infection. Under the action of pathogenic factors, the integrity of alveolar epithelial cells is disrupted, and the cells are rearranged, causing morphological and physiological changes in the cells. In addition, the phenotype of some epithelial cells is changed, and alveolar epithelial cells transform into mesenchymal cells. Alveolar epithelial cell-mesenchymal cell transdifferentiation is considered to be one of the important mechanisms of PF [97, 98].

Epithelial-mesenchymal transition (EMT) refers to the biological process in which epithelial cells are transformed into cells with a mesenchymal phenotype through specific procedures $[99,100]$. EMT plays an important role in embryonic development, chronic inflammation, tissue reconstruction, cancer metastasis, and fibrotic diseases [100-102]. The main features of EMT are the decreased expression of cell adhesion molecules (such as E-cadherin), the conversion of the cytokeratin cytoskeleton into a vimentin-based cytoskeleton, and the acquisition of morphological characteristics of mesenchymal cells $[103,104]$. During the EMT process, epithelial cells lose epithelial phenotypic characteristics, such as the ability to connect to the basement membrane, and acquire mesenchymal phenotypic characteristics, such as high migration and invasion capabilities, resistance to apoptosis, and the ability to degrade extracellular matrix [103, 104]. TGF- $\beta /$ Smad is one of the main signaling pathways that promote EMT, and it is also a classic signal transduction pathway for the occurrence of pulmonary fibrosis [105]. In the TGF- $\beta /$ Smad signaling pathway, Smad3 plays a particularly important role in the development of PF [105]. In addi- tion, zinc finger E-box binding homeobox (ZEB) is the main regulator of TGF $\beta$-mediated signaling pathways. TGF $\beta$ and its downstream signal factor Smad3 upregulate the expression of ZEBs, and signal transduction pathways such as p38/MAPKs can also induce or synergistically induce EMT transdifferentiation signal transduction in alveolar type II epithelial cells to cause the upregulation of ZEB protein expression $[105,106]$. ZEB exerts an inhibitory effect on the expression of E-cadherin by binding with the promoter of E-cadherin, and then AT-II cells transdifferentiate from epithelial cells to mesenchymal cells $[105,106]$. Zhou et al. [107] confirmed that alveolar epithelial cells could increase the level of reactive oxygen species (ROS) in mitochondria under hypoxia, and ROS could upregulate the expression of HIF- $1 \alpha$ and TGF- $\beta 1$ and promote the progression of EMT. Du et al. [108] confirmed that atorvastatin could attenuate paraquatinduced pulmonary fibrosis by downregulating the HIF$1 \alpha / \beta$-catenin pathway and inhibiting EMT.

\section{Strategies to Reduce Acute Lung Injury by Inhibiting HIF-1 (Table 1)}

7.1. Low-Molecular-Weight Heparin (LMWH). Heparin includes unfractionated heparin and LMWH [109]. LMWH is a class of low molecular weight heparin prepared by depolymerization of ordinary heparin. LMWH is a promising anticoagulant due to its excellent antithrombotic effect, high bioavailability, and low bleeding risk [109]. Due to its antiinflammatory properties, LMWH can significantly reduce the permeability of microvessels, the migration of neutrophils, the expression of the lung plasminogen activator inhibitor 1 (PAI-1) gene, and the production of active PAI-1 and stabilize the dysregulated coagulation and fibrinolytic systems [110]. Previous studies have shown that LMWH prevents endotoxin-induced ALI and suppresses systemic inflammation $[111,112]$. Severe inflammation leads to the activation of coagulation, and coagulation also affects the progression of inflammation. Accumulating evidence shows that inflammation and coagulation interact with each other [113-115]. Heparin has been shown to have both anticoagulant and anti-inflammatory effects [116]. Li et al. reported that LMWH can inhibit the expression of HIF-1 $\alpha$, VEGF, and TGF- $\beta 1$ and have an anti-inflammatory effect. Li et al. [117] indicated that LMWH inhibits oxidative stress, inflammation, and apoptosis and leads to substantial improvements in pathological, physiological, and functional impairments by inhibiting HIF- $1 \alpha$ signaling.

7.2. Emodin. Rheum officinale, a traditional Chinese medicine (TCM), has been used to treat pulmonary diseases in China for over a thousand years and can ameliorate inflammatory responses [118]. Emodin, one of the main active components of Rheum officinale, has a variety of biological activities, including anti-inflammatory, antioxidant, antitumor, and vasodilating activities [36, 119-121]. Emodin can reduce the expression of $\mathrm{NF}-\kappa \mathrm{B}$, thereby reducing the inflammatory response in ALI [122]. Mammalian target of rapamycin (mTOR) is involved in the regulation of the biological activities of pulmonary vascular endothelial cells and alveolar 
TABLE 1: The main treatments for ALI and their principal mechanisms.

\begin{tabular}{|c|c|}
\hline Treatment agents & Principal mechanisms \\
\hline LMWH & $\begin{array}{l}\text { LMWH inhibits oxidative stress, inflammation, and apoptosis by inhibiting } \\
\text { HIF- } 1 \alpha \text { signaling. }\end{array}$ \\
\hline Emodin & $\begin{array}{l}\text { Emodin reduces inflammation through inhibiting the NF- } \kappa \text { B expression } \\
\text { and mTOR/HIF- } \alpha \text { /VEGF signaling pathway. }\end{array}$ \\
\hline Atorvastatin & $\begin{array}{l}\text { Atorvastatin inhibits the EMT process by inhibiting the HIF-1 } \alpha / \beta \text {-catenin pathway } \\
\text { and reducing PF after ALI. }\end{array}$ \\
\hline $\mathrm{PHC}$ & $\begin{array}{l}\text { PHC downregulates inflammatory factors by inhibiting HIF-1 } \alpha \text {, IL-1 } \beta \text {, } \\
\text { and IL- } 6 \text { expression. }\end{array}$ \\
\hline Insulin and PEG- $b$-(PELG- $g$-PLL) & $\begin{array}{l}\text { Insulin and PEG- } b \text {-(PELG- } g \text {-PLL) inhibit the activation of HIF- } 1 \alpha \text { to reduce the activity } \\
\text { of MPO and reduce the expression of VEGF by downregulating HIF- } 1 \alpha \text { to decrease } \\
\text { the inflammatory response. }\end{array}$ \\
\hline $3,5,4^{\prime}$-Tri-O-acetylresveratrol & $\begin{array}{l}\text { 3,5, } 4^{\prime} \text {-tri-O-acetylresveratrol exhibited a protective effect on ALI by inhibiting oxidative } \\
\text { stress and the inflammatory response, which may also involve the suppression of HIF-1 } \alpha \text {. }\end{array}$ \\
\hline TIIA & $\begin{array}{l}\text { (1) TIIA blocks the synthesis of HIF- } 1 \alpha \text { protein by inhibiting the PI3K/AKT } \\
\text { and MAPK pathways and related protein translation regulators such as p70S6K1, } \\
\text { S6 ribosomal proteins, } 4 \mathrm{E}-\mathrm{BP} 1 \text {, and eIF4E; (2) TIIA enhances the protein degradation } \\
\text { of HIF- } 1 \alpha \text { through the proteasome pathway. }\end{array}$ \\
\hline COMP-Ang1 & COMP-Ang1 reduces ALI by inhibiting HIF- $1 \alpha$ and oxidative stress. \\
\hline Propofol & Propofol reduces inflammatory cytokine expression and inhibits apoptosis by inhibiting HIF- $1 \alpha$. \\
\hline
\end{tabular}

epithelial cells in ALI and therefore plays an important role in the occurrence and development of ALI [123, 124]. The activation of the mTOR signaling pathway may regulate the translocation of HIF- $1 \alpha$ from the cytoplasm to the nucleus, thereby increasing the expression of VEGF, increasing the production of inflammatory factors, and exacerbating ALI [123, 125]. Li et al. [126] showed that emodin can improve the pathological changes in ALI induced by lipopolysaccharide through the $\mathrm{mTOR} / \mathrm{HIF}-1 \alpha / \mathrm{VEGF}$ signaling pathway and significantly reduce the expression of various inflammatory factors, including TNF- $\alpha$, IL- $1 \beta$, and IL-6.

7.3. Atorvastatin. Statins are a class of 3-hydroxy-3-methylglutaryl-coenzyme A (HMG-CoA) reductase inhibitors that are widely used in lipid-lowering drugs [127]. In recent years, in addition to the lipid-lowering effects of statins, their pleiotropic effects have also received increasing attention [128, 129]. Statins have been found to be beneficial for patients with chronic obstructive pulmonary disease, pneumonia, and pulmonary fibrosis [130-132]. Statins accelerated ubiquitin/proteasome-dependent degradation of HIF-1 $\alpha$ [133]. Atorvastatin is a commonly used statin that has a significant protective effect against lung injury and PF [134-136]. Du et al. [108] found that atorvastatin could reduce ALI and PF caused by paraquat. Mechanistically, atorvastatin inhibits the EMT process by inhibiting the HIF- $1 \alpha / \beta$-catenin pathway and reducing PF after ALI.

7.4. Penehyclidine Hydrochloride (PHC). PHC is a selective anticholinergic drug that acts on $M$ receptor subtypes (M1, $\mathrm{M} 2$, and M3), and it is most selective for M1 and M3 receptors and less effective on the M2 receptor [137]. PHC can alleviate pulmonary capillary spasm, improve local microcirculation, reduce edema, and inhibit the production of inflammatory mediators $[138,139]$. Previous studies have found that PHC could reduce renal ischemia/reperfusion-induced ALI, inhibit inflammation through the NF- $\kappa$ B pathway, and improve the leakage of pulmonary blood vessels in lung tissue [140]. In addition, PHC has been suggested to ameliorate severe pancreatitis-related acute lung injury (PALI) by inhibiting the expression of inflammatory factors [141, 142]. Zhu et al. [143] showed that PHC could downregulate inflammatory factors such as NF- $\kappa \mathrm{B}$ and ILs by inhibiting HIF- $1 \alpha$, IL- $1 \beta$, and IL-6 expression, thereby improving ALI.

7.5. Insulin and PEG-b-(PELG-g-PLL). Insulin pretreatment can reduce ALI mediated by influenza virus infection [144]. However, the half-life of insulin is short, the dose is difficult to control, and frequent insulin injections increase the suffering of the patient. Tong et al. [145] used the block copolymer PEG- $b$-(PELG- $g$-PLL), which serves as a carrier, protects insulin from rapid degradation in the body, and can reinforce efficacy and reduce dosage and side effects. Insulin and PEG$b$-(PELG- $g$-PLL) treatments are significantly protected against RI/R-induced ALI in rats. Insulin and insulin/PEG$b$-(PELG- $g$-PLL) pretreatment can inhibit the activation of HIF- $1 \alpha$ to reduce the activity of MPO and reduce the expression of VEGF by downregulating HIF- $1 \alpha$ to decrease the inflammatory response in pulmonary tissues [145].

7.6. 3,5,4' ${ }^{\prime}$-Tri-O-Acetylresveratrol. Resveratrol is a polyphenol extracted from plants especially Chinese traditional medicine such as knotweed, grapes, and nuts [146]. Resveratrol has a variety of pharmacological effects, such as antitumor, immunoregulatory, anti-inflammatory, antioxidant, and neuroprotective effects [147-151]. 3,5, $4^{\prime}$-Tri-O-acetylresveratrol is the precursor of resveratrol, which overcomes the shortcomings of resveratrol, including weak pharmacokinetics, low bioavailability, and short-lived biological half-life [152]. Chiang et al. [127] showed that pretreatment with 
different doses of 3,5,4' -tri-O-acetylresveratrol improved seawater-induced lung histopathological changes, alleviated lung edema, reduced the production of inflammatory mediators, including TNF- $\alpha$ and IL-1 $\beta$, inhibited malonaldehyde (MDA) activity, and enhanced total superoxide dismutase (T-SOD) activity, which was possibly associated with the inhibition of NF- $\kappa$ B and HIF- $1 \alpha .3,5,4^{\prime}$-Tri-O-acetylresveratrol exhibited a protective effect on ALI by inhibiting oxidative stress and the inflammatory response, which may also involve the suppression of HIF- $1 \alpha$ [127].

7.7. Tanshinone IIA. Danshen is a common herbal medicine that has been used clinically in China and many other Asian countries to prevent or control cardiovascular diseases [153]. Tanshinone IIA (TIIA), a derivative of phenanthrenequinone and one of the key components of Danshen, has been reported to have immunoregulatory, anti-inflammatory, and antioxidative properties [154, 155]. TIIA can alleviate lipopolysaccharide-induced ALI by inhibiting HIF- $1 \alpha$ [156]. The possible mechanisms by which TIIA downregulates the expression of HIF-1 $\alpha$ [156] are as follows: (1) TIIA cannot inhibit lipopolysaccharide-induced HIF- $1 \alpha$ mRNA expression, but TIIA blocks the synthesis of HIF- $1 \alpha$ protein by inhibiting the PI3K/AKT and MAPK pathways and related protein translation regulators such as $\mathrm{p} 70 \mathrm{~S} 6 \mathrm{~K} 1, \mathrm{~S} 6$ ribosomal proteins, 4E-BP1, and eIF4E. (2) TIIA enhances the protein degradation of HIF- $1 \alpha$ through the proteasome pathway.

7.8. COMP-Ang1. Angiopoietin-1 (Ang I) has potential therapeutic applications in inducing angiogenesis, enhancing endothelial cell survival, and stimulating and vascular stabilization [157]. Ang I also reduces the cytokine-induced expression of ICAM-1, vascular cell adhesion molecule 1 (VCAM-1), E-selectin, and tissue factors, thereby affecting the activation of endothelial cells and the adhesion and migration of leukocytes [158]. However, the aggregation and insolubility caused by the high-level structure of disulfide bonds hinder the production of Ang I. Cho et al. [159] developed a soluble, stable, and effective variant of Ang 1 (COMPAngI). When lung tissue is exposed to oxidative stress, high levels of ROS can cause pathophysiological changes in lung tissue. ROS can induce the expression of VEGF to disrupt endothelial barrier function and subsequently increase the barrier permeability to fluids, macromolecules, and inflammatory cells $[160,161]$. In a mouse model of acute lung injury caused by hydrogen peroxide (H2O2), COMP-Ang1 was shown to significantly reduce lung injury by inhibiting HIF-1 $\alpha$ [162].

7.9. Propofol. Propofol (2,6-di-isopropylphenol) is a widely used intravenous anesthetic and sedative that is increasingly used to treat traumatic head injuries, epilepsy, delirium tremor, and asthma and to sedate critically ill patients [163]. Propofol has anti-inflammatory and antioxidant effects: it inhibits the migration, phagocytosis, and oxidation of macrophages [164]. In addition, propofol also inhibits the expression levels of a variety of inflammatory cytokines such as TNF- $\alpha$, IL- $\beta$, and IL-6 [165]. Propofol can also reduce apoptosis and upregulate the expression of endothelial nitric oxide synthase (eNOS) in human endothelial cells [166]. Propofol could alleviate acute lung injury induced by endotoxin in a mouse model of sepsis $[167,168]$. Yeh et al. [169] found that in a mouse model of endotoxin shock, a mild hypothermic dose of propofol could downregulate the expression of HIF- $1 \alpha$ and inflammatory cytokines such as IL-6, IL-8, and TNF- $\alpha$ in lung epithelial cells, thereby reducing lung injury. Propofol reduced the expression of HIF- $1 \alpha$ and its downstream proapoptotic gene BNIP3 in vitro and inhibited apoptosis in lung epithelial cells treated with lipopolysaccharide and desferrioxamine. Propofol can reduce acute lung injury by inhibiting HIF- $1 \alpha$.

\section{Conclusion}

The pathological process of ALI is very complicated and is characterized by excessive inflammation, alveolar epithelial cell apoptosis, and the destruction of the alveolar-capillary barrier, resulting in the accumulation of protein-rich pulmonary edema fluid. HIF-1 plays a major role in these processes. Exploring the role of HIF-1 in ALI and the pathogenesis of this common lung disease in a comprehensive and in-depth manner and finding ways to regulate HIF-1 will provide improved and more complete treatment for ALI.

\section{Data Availability}

The data of this manuscript are available on request from the corresponding author.

\section{Conflicts of Interest}

The authors declare that there is no potential conflict of interest associated with this manuscript.

\section{Authors' Contributions}

Yang Liu and Du Xiang contributed equally to the manuscript writing and share first authorship. Hengcheng Zhang, Hanlin Yao, and Yanfeng Wang are responsible for the revision of manuscripts. Yang Liu and Du Xiang contributed equally and share first authorship.

\section{Acknowledgments}

This manuscript was supported by the National Natural Science Foundation of China, Grant No. 81570079.

\section{References}

[1] M. Zeng, W. Sang, S. Chen et al., "4-PBA inhibits LPSinduced inflammation through regulating ER stress and autophagy in acute lung injury models," Toxicology Letters, vol. 271, pp. 26-37, 2017.

[2] N. M. Pinheiro, F. P. R. Santana, R. R. Almeida et al., "Acute lung injury is reduced by the $\alpha 7 \mathrm{nAChR}$ agonist PNU-282987 through changes in the macrophage profile," The FASEB Journal, vol. 31, no. 1, pp. 320-332, 2016. 
[3] Y. Butt, A. Kurdowska, and T. C. Allen, "Acute lung injury: a clinical and molecular review," Archives of Pathology \& Laboratory Medicine, vol. 140, no. 4, pp. 345-350, 2016.

[4] F. Du, P. Jiang, S. He, D. Song, and F. Xu, "Antiplatelet therapy for critically ill patients," Shock, vol. 49, no. 6, pp. 616-624, 2018.

[5] C. M. Hendrickson and M. A. Matthay, "Endothelial biomarkers in human sepsis: pathogenesis and prognosis for ARDS," Pulmonary Circulation, vol. 8, no. 2, article 767777836, 2018.

[6] M. He, W. Shi, M. Yu et al., "Nicorandil attenuates LPSinduced acute lung injury by pulmonary endothelial cell protection via NF- $\kappa \mathrm{B}$ and MAPK pathways," Oxidative Medicine and Cellular Longevity, vol. 2019, Article ID 4957646, 13 pages, 2019.

[7] M. Kellner, S. Noonepalle, Q. Lu, A. Srivastava, E. Zemskov, and S. M. Black, "ROS signaling in the pathogenesis of acute lung injury (ALI) and acute respiratory distress syndrome (ARDS)," Advances in Experimental Medicine and Biology, vol. 967, pp. 105-137, 2017.

[8] W. Xia, Z. Pan, H. Zhang, Q. Zhou, and Y. Liu, "Inhibition of $\mathrm{ERR} \alpha$ aggravates sepsis-induced acute lung injury in rats via provoking inflammation and oxidative stress," Oxidative Medicine and Cellular Longevity, vol. 2020, Article ID 2048632, 9 pages, 2020.

[9] G. L. Semenza and G. L. Wang, "A nuclear factor induced by hypoxia via de novo protein synthesis binds to the human erythropoietin gene enhancer at a site required for transcriptional activation," Molecular and Cellular Biology, vol. 12, no. 12, pp. 5447-5454, 1992.

[10] F. Yu, L. J. Tong, and D. S. Cai, "Sevoflurane inhibits neuronal apoptosis and expressions of HIF-1 and HSP70 in brain tissues of rats with cerebral ischemia/reperfusion injury," European Review for Medical and Pharmacological Sciences, vol. 24, no. 9, pp. 5082-5090, 2020.

[11] H. Talwar, C. Bauerfeld, Y. Liu, and L. Samavati, "The dataset describes: HIF-1 $\alpha$ expression and LPS mediated cytokine production in MKP-1 deficient bone marrow derived murine macrophages," Data in Brief, vol. 14, pp. 56-61, 2017.

[12] P. Horak, A. R. Crawford, D. D. Vadysirisack et al., "Negative feedback control of HIF-1 through REDD1-regulated ROS suppresses tumorigenesis," Proceedings of the National Academy of Sciences of the United States of America, vol. 107, no. 10, pp. 4675-4680, 2010.

[13] G. L. Semenza, "HIF-1: mediator of physiological and pathophysiological responses to hypoxia," Journal of Applied Physiology (Bethesda, MD: 1985), vol. 88, no. 4, pp. 1474-1480, 2000 .

[14] L. A. Heger, M. Kerber, M. Hortmann et al., "Expression of the oxygen-sensitive transcription factor subunit HIF- $1 \alpha$ in patients suffering from secondary Raynaud syndrome," Acta Pharmacologica Sinica, vol. 40, no. 4, pp. 500-506, 2019.

[15] D. Kenchegowda, B. Natale, M. A. Lemus, D. R. Natale, and S. A. Fisher, "Inactivation of maternal_Hif-1 $\alpha_{-}$at midpregnancy causes placental defects and deficits in oxygen delivery to the fetal organs under hypoxic stress," Developmental Biology, vol. 422, no. 2, pp. 171-185, 2017.

[16] Y. Zhang, X. Dong, and K. Lingappan, "Role of HIF-1 $\alpha$ miR30a-Snail axis in neonatal hyperoxic lung injury," Oxidative Medicine and Cellular Longevity, vol. 2019, Article ID 8327486, 9 pages, 2019.
[17] T. Yin, S. He, G. Shen, and Y. Wang, "HIF-1 dimerization inhibitor acriflavine enhances antitumor activity of sunitinib in breast cancer model," Oncology Research, vol. 22, no. 3, pp. 139-145, 2014.

[18] X. Jin, L. Dai, Y. Ma, J. Wang, and Z. Liu, "Implications of HIF- $1 \alpha$ in the tumorigenesis and progression of pancreatic cancer," Cancer Cell International, vol. 20, no. 1, article 273, 2020.

[19] G. N. Masoud and W. Li, "HIF-1 $\alpha$ pathway: role, regulation and intervention for cancer therapy," Acta Pharmaceutica Sinica B, vol. 5, no. 5, pp. 378-389, 2015.

[20] D. Tarade and M. Ohh, "The HIF and other quandaries in VHL disease," Oncogene, vol. 37, no. 2, pp. 139-147, 2018.

[21] L. Singh, S. Aldosary, A. S. Saeedan, M. N. Ansari, and G. Kaithwas, "Prolyl hydroxylase 2: a promising target to inhibit hypoxia-induced cellular metabolism in cancer cells," Drug Discovery Today, vol. 23, no. 11, pp. 1873-1882, 2018.

[22] E. L. Bell, B. M. Emerling, and N. S. Chandel, "Mitochondrial regulation of oxygen sensing," Mitochondrion, vol. 5, no. 5, pp. 322-332, 2005.

[23] J. Li, W. Xi, X. Li, H. Sun, and Y. Li, “Advances in inhibition of protein-protein interactions targeting hypoxia- inducible factor-1 for cancer therapy," Bioorganic \& Medicinal Chemistry, vol. 27, no. 7, pp. 1145-1158, 2019.

[24] A. T. McLaren, P. A. Marsden, C. D. Mazer et al., "Increased expression of HIF- $1 \alpha, \mathrm{nNOS}$, and VEGF in the cerebral cortex of anemic rats," American Journal of PhysiologyRegulatory, Integrative and Comparative Physiology, vol. 292, no. 1, pp. R403-R414, 2007.

[25] D. Greenald, J. Jeyakani, B. Pelster, I. Sealy, S. Mathavan, and F. J. van Eeden, "Genome-wide mapping of Hif- $1 \alpha$ binding sites in zebrafish," BMC Genomics, vol. 16, no. 1, p. 923, 2015.

[26] C. J. Lin, Y. M. Lan, M. Q. Ou, L. Q. Ji, and S. D. Lin, "Expression of miR-217 and HIF-1 $\alpha$ /VEGF pathway in patients with diabetic foot ulcer and its effect on angiogenesis of diabetic foot ulcer rats," Journal of Endocrinological Investigation, vol. 42, no. 11, pp. 1307-1317, 2019.

[27] D. Hasan, E. Gamen, N. Abu Tarboush, Y. Ismail, O. Pak, and B. Azab, "PKM2 and HIF- $1 \alpha$ regulation in prostate cancer cell lines," PLoS One, vol. 13, no. 9, article e0203745, 2018.

[28] J. C. Morote-Garcia, P. Rosenberger, J. Kuhlicke, and H. K. Eltzschig, "HIF-1-dependent repression of adenosine kinase attenuates hypoxia-induced vascular leak," Blood, vol. 111, no. 12, pp. 5571-5580, 2008.

[29] R. Archid, W. Solass, C. Tempfer et al., "Cachexia anorexia syndrome and associated metabolic dysfunction in peritoneal metastasis," International Journal of Molecular Sciences, vol. 20, no. 21, p. 5444, 2019.

[30] L. Camacho-Jimenez, L. Leyva-Carrillo, A. B. PeregrinoUriarte, J. L. Duarte-Gutierrez, M. Tresguerres, and G. YepizPlascencia, "Regulation of glyceraldehyde-3-phosphate dehydrogenase by hypoxia inducible factor 1 in the white shrimp_Litopenaeus vannamei_during hypoxia and reoxygenation," Comparative Biochemistry and Physiology, Part A: Molecular \& Integrative Physiology, vol. 235, pp. 56-65, 2019.

[31] Z. Liu, L. Guo, R. Li et al., "Transforming growth factor- $\beta 1$ and hypoxia inducible factor- $1 \alpha$ synergistically inhibit the osteogenesis of periodontal ligament stem cells," International Immunopharmacology, vol. 75, article 105834, 2019.

[32] Y. Yu, L. Ma, H. Zhang et al., "EPO could be regulated by HIF-1 and promote osteogenesis and accelerate bone repair," 
Artificial Cells, Nanomedicine, and Biotechnology, vol. 48, no. 1, pp. 206-217, 2020.

[33] L. Yang, D. Wang, X. T. Wang, Y. P. Lu, and L. Zhu, “The roles of hypoxia-inducible factor-1 and iron regulatory protein 1 in iron uptake induced by acute hypoxia," Biochemical and Biophysical Research Communications, vol. 507, no. 1-4, pp. 128-135, 2018.

[34] Y. K. Choi, J. H. Park, J. A. Yun et al., "Heme oxygenase metabolites improve astrocytic mitochondrial function via a Ca2+-dependent HIF- $1 \alpha /$ ERR $\alpha$ circuit," PLoS One, vol. 13, no. 8, article e0202039, 2018.

[35] C. Matrone, G. Pignataro, P. Molinaro et al., "HIF-1alpha reveals a binding activity to the promoter of iNOS gene after permanent middle cerebral artery occlusion," Journal of Neurochemistry, vol. 90, no. 2, pp. 368-378, 2004.

[36] Z. Li, Y. Lin, S. Zhang et al., "Emodin regulates neutrophil phenotypes to prevent hypercoagulation and lung carcinogenesis," Journal of Translational Medicine, vol. 17, no. 1, p. 90, 2019.

[37] C. Qian, Y. Dai, X. Xu, and Y. Jiang, "HIF- $1 \alpha$ regulates proliferation and invasion of oral cancer cells through Kv3.4 channel," Annals of Clinical and Laboratory Science, vol. 49, no. 4, pp. 457-467, 2019.

[38] C. C. Wykoff, C. W. Pugh, A. L. Harris, P. H. Maxwell, and P. J. Ratcliffe, "The HIF pathway: implications for patterns of gene expression in cancer," Novartis Foundation Symposium, vol. 240, pp. 212-225, 2008.

[39] E. Burgos-Morón, Z. Abad-Jiménez, A. M. Marañón et al., "Relationship between oxidative stress, ER stress, and inflammation in type 2 diabetes: the battle continues," Journal of Clinical Medicine, vol. 8, no. 9, article 1385, 2019.

[40] V. Larosa and C. Remacle, "Insights into the respiratory chain and oxidative stress," Bioscience Reports, vol. 38, no. 5, 2018.

[41] F. Augsburger, A. Filippova, and V. Jaquet, "Methods for detection of NOX-derived superoxide radical anion and hydrogen peroxide in cells," Methods in Molecular Biology, vol. 1982, pp. 233-241, 2019.

[42] W. S. Yang and B. R. Stockwell, "Ferroptosis: death by lipid peroxidation," Trends in Cell Biology, vol. 26, no. 3, pp. 165-176, 2016.

[43] B. Wang, H. Zhang, J. An et al., "Sequential intercellular delivery Nanosystem for enhancing ROS-induced antitumor therapy," Nano Letters, vol. 19, no. 6, pp. 3505-3518, 2019.

[44] B. Kalyanaraman, G. Cheng, M. Hardy, O. Ouari, B. Bennett, and J. Zielonka, "Teaching the basics of reactive oxygen species and their relevance to cancer biology: mitochondrial reactive oxygen species detection, redox signaling, and targeted therapies," Redox Biology, vol. 15, pp. 347-362, 2018.

[45] S. I. Liochev, "Reactive oxygen species and the free radical theory of aging," Free Radical Biology \& Medicine, vol. 60, pp. 1-4, 2013.

[46] B. Halliwell, "Free radicals and antioxidants: updating a personal view," Nutrition Reviews, vol. 70, no. 5, pp. 257-265, 2012.

[47] H. He, L. Wang, Y. Qiao et al., "Doxorubicin induces endotheliotoxicity and mitochondrial dysfunction via ROS/eNOS/NO pathway," Frontiers in Pharmacology, vol. 10, article 1531, 2020.

[48] D. Burtenshaw, M. Kitching, E. M. Redmond, I. L. Megson, and P. A. Cahill, "Reactive oxygen species (ROS), intimal thickening, and subclinical atherosclerotic disease," Frontiers in Cardiovascular Medicine, vol. 6, p. 89, 2019.
[49] Y. Lu and A. I. Cederbaum, "Cytochrome P450s and alcoholic liver disease," Current Pharmaceutical Design, vol. 24, no. 14, pp. 1502-1517, 2018.

[50] R. Chattopadhyay, A. Tinnikov, E. Dyukova et al., "Withdrawal: 12/15-lipoxygenase-dependent ROS production is required for diet-induced endothelial barrier dysfunction," Journal of Lipid Research, vol. 60, no. 4, p. 909, 2019.

[51] S. Barangi, A. W. Hayes, and G. Karimi, "The more effective treatment of atrial fibrillation applying the natural compounds; as NADPH oxidase and ion channel inhibitors," Critical Reviews in Food Science and Nutrition, vol. 58, no. 7, pp. 1230-1241, 2018.

[52] Y. Ji, C. Yang, Z. Tang et al., “Adenylate kinase hCINAP determines self-renewal of colorectal cancer stem cells by facilitating LDHA phosphorylation," Nature Communications, vol. 8, no. 1, article 15308, 2017.

[53] J. Liang and B. Liu, "ROS-responsive drug delivery systems," Bioengineering \& Translational Medicine, vol. 1, no. 3, pp. 239-251, 2016.

[54] I. Y. Petrushanko, V. M. Lobachev, A. S. Kononikhin et al., "Oxidation of $\mathrm{Ca} 2+$-binding domain of NADPH oxidase 5 (NOX5): toward understanding the mechanism of inactivation of NOX5 by ROS," PLoS One, vol. 11, no. 7, article e0158726, 2016.

[55] E. Meiyanto, H. Putri, Y. Arum Larasati et al., "Anti-proliferative and anti-metastatic potential of curcumin analogue, pentagamavunon-1 (PGV-1), toward highly metastatic breast cancer cells in correlation with ROS generation," Advanced Pharmaceutical Bulletin, vol. 9, no. 3, pp. 445-452, 2019.

[56] D. Bazopoulou, D. Knoefler, Y. Zheng et al., "Developmental ROS individualizes organismal stress resistance and lifespan," Nature, vol. 576, no. 7786, pp. 301-305, 2019.

[57] P. Ziltener, T. Reinheckel, and A. Oxenius, "Neutrophil and alveolar macrophage-mediated innate immune control of legionella pneumophila lung infection via TNF and ROS," PLoS Pathogens, vol. 12, no. 4, article e1005591, 2016.

[58] M. S. Hossain and K. J. Dietz, "Tuning of redox regulatory mechanisms, reactive oxygen species and redox homeostasis under salinity stress," Frontiers in Plant Science, vol. 7, p. $548,2016$.

[59] C.-W. Chow, M. T. Herrera Abreu, T. Suzuki, and G. P. Downey, "Oxidative stress and acute lung injury," American Journal of Respiratory Cell and Molecular Biology, vol. 29, no. 4, pp. 427-431, 2003.

[60] T. Liu and D. Zhao, "Research progress of role of reactive oxygen species in acute lung injury acute respiratory distress syndrome," International Journal of Respiratory, vol. 39, pp. 1890-1894, 2019.

[61] W. J. Zhang, H. Wei, Y. T. Tien, and B. Frei, "Genetic ablation of phagocytic NADPH oxidase in mice limits TNF $\alpha$-induced inflammation in the lungs but not other tissues," Free Radical Biology \& Medicine, vol. 50, no. 11, pp. 1517-1525, 2011.

[62] Y. N. Li, M. M. Xi, Y. Guo, C. X. Hai, W. L. Yang, and X. J. Qin, "NADPH oxidase-mitochondria axis-derived ROS mediate arsenite-induced HIF- $1 \alpha$ stabilization by inhibiting prolyl hydroxylases activity," Toxicology Letters, vol. 224, no. 2, pp. 165-174, 2014.

[63] N. R. Prabhakar, G. K. Kumar, J. Nanduri, and G. L. Semenza, "ROS signaling in systemic and cellular responses to chronic intermittent hypoxia," Antioxidants \& Redox Signaling, vol. 9, no. 9, pp. 1397-1404, 2007. 
[64] Y. Wang, J. Ma, H. Shen et al., "Reactive oxygen species promote ovarian cancer progression via the HIF-1 $\alpha / \mathrm{LOX} / \mathrm{E}-$ cadherin pathway," Oncology Reports, vol. 32, no. 5, pp. 2150-2158, 2014.

[65] E. Klumpen, N. Hoffschroer, B. Zeis, U. Gigengack, E. Dohmen, and R. J. Paul, "Reactive oxygen species (ROS) and the heat stress response of Daphnia pulex: ROS-mediated activation of hypoxia-inducible factor 1 (HIF-1) and heat shock factor 1 (HSF-1) and the clustered expression of stress genes," Biology of the Cell, vol. 109, no. 1, pp. 39-64, 2017.

[66] S. Bonello, C. Zähringer, R. S. BelAiba et al., "Reactive oxygen species activate the HIF- $1 \alpha$ promoter via a functional NF $\kappa$ B site," Arteriosclerosis, Thrombosis, and Vascular Biology, vol. 27, no. 4, pp. 755-761, 2007.

[67] I. Papandreou, R. A. Cairns, L. Fontana, A. L. Lim, and N. C. Denko, "HIF-1 mediates adaptation to hypoxia by actively downregulating mitochondrial oxygen consumption," Cell Metabolism, vol. 3, no. 3, pp. 187-197, 2006.

[68] J. W. Kim, I. Tchernyshyov, G. L. Semenza, and C. V. Dang, "HIF-1-mediated expression of pyruvate dehydrogenase kinase: a metabolic switch required for cellular adaptation to hypoxia," Cell Metabolism, vol. 3, no. 3, pp. 177-185, 2006.

[69] X. Yang, M. Zhong, J. Chen, T. Li, Q. Cheng, and Y. Dai, "HIF-1<alpha> repression of PTEN transcription mediates protective effects of BMSCs on neurons during hypoxia," Neuroscience, vol. 392, pp. 57-65, 2018.

[70] M. Guo, X. Ma, Y. Feng et al., "In chronic hypoxia, glucose availability and hypoxic severity dictate the balance between HIF-1 and HIF-2 in astrocytes," The FASEB Journal, vol. 33, no. 10, pp. 11123-11136, 2019.

[71] G. L. Semenza, "Hypoxia-inducible factor 1: regulator of mitochondrial metabolism and mediator of ischemic preconditioning," Biochimica et Biophysica Acta (BBA) - Molecular Cell Research, vol. 1813, no. 7, pp. 1263-1268, 2011.

[72] R. Fukuda, H. Zhang, J. W. Kim, L. Shimoda, C. V. Dang, and G. L. Semenza, "HIF-1 regulates cytochrome oxidase subunits to optimize efficiency of respiration in hypoxic cells," Cell, vol. 129, no. 1, pp. 111-122, 2007.

[73] G. L. Semenza, B. H. Jiang, S. W. Leung et al., "Hypoxia response elements in the aldolase $\mathrm{A}$, enolase 1 , and lactate dehydrogenase A gene promoters contain essential binding sites for hypoxia-inducible factor 1," The Journal of Biological Chemistry, vol. 271, no. 51, pp. 32529-32537, 1996.

[74] H. Zhang, M. Bosch-Marce, L. A. Shimoda et al., "Mitochondrial autophagy is an HIF-1-dependent adaptive metabolic response to hypoxia," The Journal of Biological Chemistry, vol. 283, no. 16, pp. 10892-10903, 2008.

[75] S. Y. Chan, Y. Y. Zhang, C. Hemann, C. E. Mahoney, J. L. Zweier, and J. Loscalzo, "MicroRNA-210 controls mitochondrial metabolism during hypoxia by repressing the ironsulfur cluster assembly proteins ISCU1/2," Cell Metabolism, vol. 10, no. 4, pp. 273-284, 2009.

[76] H. Lin and F. Jin, "Advancement of pathological role of hypoxia-inducible factor 1 in acute lung injury," International Journal of Respiratory, vol. 39, pp. 1885-1889, 2019.

[77] Y. Li, Y. Liu, C. Wang et al., "Succinate induces synovial angiogenesis in rheumatoid arthritis through metabolic remodeling and HIF-1 $\alpha$ /VEGF axis," Free Radical Biology \& Medicine, vol. 126, pp. 1-14, 2018.

[78] C. G. Lee, H. Link, P. Baluk et al., "Vascular endothelial growth factor (VEGF) induces remodeling and enhances
$\mathrm{T}_{\mathrm{H}}$ 2-mediated sensitization and inflammation in the lung," Nature Medicine, vol. 10, no. 10, pp. 1095-1103, 2004.

[79] X. X. S Li, M. Jiang, Y. Bi, J. Xu, and M. Han, "Lipopolysaccharide induces inflammation and facilitates lung metastasis in a breast cancer model via the prostaglandin E2-EP2 pathway," Molecular Medicine Reports, vol. 11, no. 6, pp. 44544462, 2015.

[80] S. R. Kim, K. S. Lee, H. S. Park et al., "HIF- $1 \alpha$ inhibition ameliorates an allergic airway disease via VEGF suppression in bronchial epithelium," European Journal of Immunology, vol. 40, no. 10, pp. 2858-2869, 2010.

[81] G. Wu, G. Xu, D. W. Chen et al., "Hypoxia exacerbates inflammatory acute lung injury via the toll-like receptor 4 signaling pathway," Frontiers in Immunology, vol. 9, article 1667, 2018.

[82] B. C. Albensi, "What is nuclear factor kappa B (NF- $\kappa \mathrm{B})$ doing in and to the mitochondrion?," Frontiers in Cell and Development Biology, vol. 7, p. 154, 2019.

[83] M. Mo, S. Li, Z. Dong et al., "S-allylmercaptocysteine ameliorates lipopolysaccharide-induced acute lung injury in mice by inhibiting inflammation and oxidative stress via nuclear factor kappa B and Keap1/Nrf2 pathways," International Immunopharmacology, vol. 81, article 106273, 2020.

[84] R. Chen, F. Xie, J. Zhao, and B. Yue, "Suppressed nuclear factor-kappa B alleviates lipopolysaccharide-induced acute lung injury through downregulation of CXCR4 mediated by microRNA-194," Respiratory Research, vol. 21, no. 1, p. 144, 2020.

[85] Y. J. Jung, J. S. Isaacs, S. Lee, J. Trepel, and L. Neckers, "IL-1beta-mediated up-regulation of HIF-1alpha via an NFkappaB/COX-2 pathway identifies HIF-1 as a critical link between inflammation and oncogenesis," The FASEB Journal, vol. 17, no. 14, pp. 2115-2117, 2003.

[86] N. Gupta and V. Nizet, "Stabilization of hypoxia-inducible Factor-1 alpha augments the therapeutic capacity of bone marrow-derived mesenchymal stem cells in experimental pneumonia," Frontiers in Medicine, vol. 5, p. 131, 2018.

[87] J. Lan, H. Lu, D. Samanta, S. Salman, Y. Lu, and G. L. Semenza, "Hypoxia-inducible factor 1-dependent expression of adenosine receptor $2 \mathrm{~B}$ promotes breast cancer stem cell enrichment," Proceedings of the National Academy of Sciences of the United States of America, vol. 115, no. 41, pp. E9640E9648, 2018.

[88] T. Eckle, E. M. Kewley, K. S. Brodsky et al., "Identification of hypoxia-inducible factor HIF-1A as transcriptional regulator of the A2B adenosine receptor during acute lung injury," Journal of Immunology, vol. 192, no. 3, pp. 1249-1256, 2014.

[89] T. Eckle, A. Grenz, S. Laucher, and H. K. Eltzschig, "A2B adenosine receptor signaling attenuates acute lung injury by enhancing alveolar fluid clearance in mice," The Journal of Clinical Investigation, vol. 118, no. 10, pp. 3301-3315, 2008.

[90] D. Cheng, C. Zhu, Y. Liang, Y. Xing, and C. Shi, "MiR-424 overexpression protects alveolar epithelial cells from LPS-induced apoptosis and inflammation by targeting FGF2 via the NF- $\kappa \mathrm{B}$ pathway," Life Sciences, vol. 242, article 117213, 2020.

[91] S. Krick, B. G. Eul, J. Hänze et al., "Role of hypoxia-inducible factor- $1 \alpha$ in hypoxia-induced apoptosis of primary alveolar epithelial type II cells," American Journal of Respiratory Cell and Molecular Biology, vol. 32, no. 5, pp. 395-403, 2005.

[92] X. Y. He, X. Y. Shi, H. B. Yuan, H. T. Xu, Y. K. Li, and Z. Zou, "Propofol attenuates hypoxia-induced apoptosis in alveolar 
epithelial type II cells through down-regulating hypoxiainducible factor-1 $\alpha$," Injury, vol. 43, no. 3, pp. 279-283, 2012.

[93] Y. Wang, L. Ding, Z. Li, G. Chen, M. Sun, and D. Oupicky, "Treatment of acute lung injury and early- and late-stage pulmonary fibrosis with combination emulsion siRNA polyplexes," Journal of Controlled Release, vol. 314, pp. 12-24, 2019.

[94] A. J. Cunningham, "Acute respiratory distress syndrome-two decades later," The Yale Journal of Biology and Medicine, vol. 64, no. 4, pp. 387-402, 1991.

[95] L. C. Song, X. X. Chen, J. G. Meng et al., "Effects of different corticosteroid doses and durations on smoke inhalationinduced acute lung injury and pulmonary fibrosis in the rat," International Immunopharmacology, vol. 71, pp. 392403, 2019.

[96] E. L. Burnham, W. J. Janssen, D. W. H. Riches, M. Moss, and G. P. Downey, "The fibroproliferative response in acute respiratory distress syndrome: mechanisms and clinical significance," The European Respiratory Journal, vol. 43, no. 1, pp. 276-285, 2013.

[97] C. Hill, M. G. Jones, D. E. Davies, and Y. Wang, "Epithelialmesenchymal transition contributes to pulmonary fibrosis via aberrant epithelial/fibroblastic cross-talk," Journal of Lung Health and Diseases, vol. 3, no. 2, pp. 31-35, 2019.

[98] S. Y. Kyung, D. Y. Kim, J. Y. Yoon et al., "Sulforaphane attenuates pulmonary fibrosis by inhibiting the epithelialmesenchymal transition," BMC Pharmacology and Toxicology, vol. 19, no. 1, p. 13, 2018.

[99] V. Mittal, "Epithelial mesenchymal transition in tumor metastasis," Annual Review of Pathology, vol. 13, no. 1, pp. 395-412, 2018.

[100] I. Briede, I. Strumfa, A. Vanags, and J. Gardovskis, “The association between inflammation, epithelial mesenchymal transition and stemness in colorectal carcinoma," Journal of Inflammation Research, vol. 13, pp. 15-34, 2020.

[101] D. H. Kim, T. Xing, Z. Yang, R. Dudek, Q. Lu, and Y. H. Chen, "Epithelial mesenchymal transition in embryonic development, tissue repair and cancer: a comprehensive overview," Journal of Clinical Medicine, vol. 7, no. 1, p. 1, 2018.

[102] Y. L. Kuo, I. M. Jou, S. F. Jeng et al., "Hypoxia-induced epithelial-mesenchymal transition and fibrosis for the development of breast capsular contracture," Scientific Reports, vol. 9, no. 1, article 10269, 2019.

[103] Q. He, H. Li, F. Meng et al., "Methionine sulfoxide reductase B1 regulates hepatocellular carcinoma cell proliferation and invasion via the mitogen-activated protein kinase pathway and epithelial-mesenchymal transition," Oxidative Medicine and Cellular Longevity, vol. 2018, Article ID 5287971, 15 pages, 2018.

[104] Y. Yang, P. Zhang, R. Yan et al., "MnTE-2-PyP attenuates TGF- $\beta$-induced epithelial-mesenchymal transition of colorectal cancer cells by inhibiting the Smad2/3 signaling pathway," Oxidative Medicine and Cellular Longevity, vol. 2019, Article ID 8639791, 11 pages, 2019.

[105] L. Xue, D. Deng, S. Zheng et al., "Design, synthesis and discovery of $2(1 \mathrm{H})$-quinolone derivatives for the treatment of pulmonary fibrosis through inhibition of TGF- $\beta /$ smad dependent and independent pathway," European Journal of Medicinal Chemistry, vol. 197, article 112259, 2020.

[106] M. Xiong, L. Jiang, Y. Zhou et al., “The miR-200 family regulates TGF- $\beta 1$-induced renal tubular epithelial to mesenchy- mal transition through Smad pathway by targeting ZEB1 and ZEB2 expression," American Journal of PhysiologyRenal Physiology, vol. 302, no. 3, pp. F369-F379, 2012.

[107] G. Zhou, L. A. Dada, M. Wu et al., "Hypoxia-induced alveolar epithelial-mesenchymal transition requires mitochondrial ROS and hypoxia-inducible factor 1," American Journal of Physiology. Lung Cellular and Molecular Physiology, vol. 297, no. 6, pp. L1120-L1130, 2009.

[108] J. du, Y. Zhu, X. Meng et al., “Atorvastatin attenuates paraquat poisoning-induced epithelial-mesenchymal transition via downregulating hypoxia-inducible factor-1 alpha," Life Sciences, vol. 213, pp. 126-133, 2018.

[109] Y. Fan, M. Jiang, D. Gong, and C. Zou, "Efficacy and safety of low-molecular-weight heparin in patients with sepsis: a metaanalysis of randomized controlled trials," Scientific Reports, vol. 6, no. 1, article 25984, 2016.

[110] L. F. Li, C. C. Huang, H. C. Lin, Y. H. Tsai, D. A. Quinn, and S. K. Liao, "Unfractionated heparin and enoxaparin reduce high-stretch ventilation augmented lung injury: a prospective, controlled animal experiment," Critical Care, vol. 13, no. 4, p. R108, 2009.

[111] Z. G. Luan, M. Naranpurev, and X. C. Ma, "Treatment of low molecular weight heparin inhibits systemic inflammation and prevents endotoxin-induced acute lung injury in rats," Inflammation, vol. 37, no. 3, pp. 924-932, 2014.

[112] F. Ning, X. Wang, L. Shang et al., "Low molecular weight heparin may prevent acute lung injury induced by sepsis in rats," Gene, vol. 557, no. 1, pp. 88-91, 2015.

[113] M. Levi and T. van der Poll, "Inflammation and coagulation," Critical Care Medicine, vol. 38, no. 2, pp. S26-S34, 2010.

[114] I. Dan-Brezis, A. Zahavi, R. Axer-Siegel et al., "Inflammation, angiogenesis and coagulation interplay in a variety of retinal diseases," Acta Ophthalmologica, vol. 98, no. 5, 2020.

[115] P. Dumnicka, D. Maduzia, P. Ceranowicz, R. Olszanecki, R. Drozdz, and B. Kusnierz-Cabala, "The interplay between inflammation, coagulation and endothelial injury in the early phase of acute pancreatitis: clinical implications," International Journal of Molecular Sciences, vol. 18, no. 2, p. 354, 2017.

[116] M. Camprubi-Rimblas, N. Tantinya, J. Bringue, R. GuillamatPrats, and A. Artigas, "Anticoagulant therapy in acute respiratory distress syndrome," Annals of Translational Medicine, vol. 6, no. 2, p. 36, 2018.

[117] L. F. Li, Y. Y. Liu, S. W. Lin et al., "Low-molecular-weight heparin reduces ventilation-induced lung injury through hypoxia inducible factor- $1 \alpha$ in a murine endotoxemia model," International Journal of Molecular Sciences, vol. 21, no. 9, p. 3097, 2020.

[118] G. Song, Y. Zhang, S. Yu et al., "Chrysophanol attenuates airway inflammation and remodeling through nuclear factorkappa B signaling pathway in asthma," Phytotherapy Research, vol. 33, no. 10, pp. 2702-2713, 2019.

[119] X. Dong, J. Fu, X. Yin et al., "Emodin: a review of its pharmacology, toxicity and pharmacokinetics," Phytotherapy Research, vol. 30, no. 8, pp. 1207-1218, 2016.

[120] B. A. Monisha, N. Kumar, and A. B. Tiku, "Emodin and its role in chronic diseases," Advances in Experimental Medicine and Biology, vol. 928, pp. 47-73, 2016.

[121] L. Fang, F. Zhao, S. Iwanowycz et al., "Anticancer activity of emodin is associated with downregulation of CD155," International Immunopharmacology, vol. 75, article 105763, 2019. 
[122] W. Zhang, X. Lu, W. Wang et al., "Inhibitory effects of emodin, thymol, and astragalin on leptospira interrogansinduced inflammatory response in the uterine and endometrium epithelial cells of mice," Inflammation, vol. 40, no. 2, pp. 666-675, 2017.

[123] Y. Hu, J. Liu, Y. F. Wu et al., "mTOR and autophagy in regulation of acute lung injury: a review and perspective," Microbes and Infection, vol. 16, no. 9, pp. 727-734, 2014.

[124] S. Üstün, C. Lassnig, A. Preitschopf et al., "Effects of the mTOR inhibitor everolimus and the PI3K/mTOR inhibitor NVP- BEZ235 in murine acute lung injury models," Transplant Immunology, vol. 33, no. 1, pp. 45-50, 2015.

[125] D. Karmpaliotis, I. Kosmidou, E. P. Ingenito et al., "Angiogenic growth factors in the pathophysiology of a murine model of acute lung injury," American Journal of Physiology-Lung Cellular and Molecular Physiology, vol. 283, no. 3, pp. L585-L595, 2002.

[126] X. Li, C. Shan, Z. Wu, H. Yu, A. Yang, and B. Tan, "Emodin alleviated pulmonary inflammation in rats with LPS-induced acute lung injury through inhibiting the mTOR/HIF$1 \alpha /$ VEGF signaling pathway," Inflammation Research, vol. 69, no. 4, pp. 365-373, 2020.

[127] K. H. Chiang, W. L. Cheng, C. M. Shih et al., "Statins, HMGCoA reductase inhibitors, improve neovascularization by increasing the expression density of CXCR4 in endothelial progenitor cells," PLoS One, vol. 10, no. 8, article e0136405, 2015.

[128] A. F. R. Tralhão, V. C. de Souza-Dantas, J. I. F. Salluh, and P. M. S. R. Póvoa, "Impact of statins in outcomes of septic patients: a systematic review," Postgraduate Medicine, vol. 126, pp. 45-58, 2015.

[129] A. Jaśkiewicz, B. Pająk, A. Litwiniuk, K. Urbańska, and A. Orzechowski, "Geranylgeraniol prevents statin-dependent myotoxicity in C2C12 muscle cells through RAP1 GTPase prenylation and cytoprotective autophagy," Oxidative Medicine and Cellular Longevity, vol. 2018, Article ID 6463807, 22 pages, 2018.

[130] A. J. N. Raymakers, M. Sadatsafavi, D. D. Sin, M. A. de Vera, and L. D. Lynd, "The impact of statin drug use on all-cause mortality in patients with COPD: a population-based cohort study," Chest, vol. 152, no. 3, pp. 486-493, 2017.

[131] F. S. Grudzinska, D. P. S. Dosanjh, D. Parekh et al., "Statin therapy in patients with community-acquired pneumonia," Clinical Medicine, vol. 17, no. 5, pp. 403-407, 2017.

[132] M. Kreuter, U. Costabel, L. Richeldi et al., "Statin therapy and outcomes in trials of nintedanib in idiopathic pulmonary fibrosis," Respiration, vol. 95, no. 5, pp. 317-326, 2018.

[133] T. Hisada, M. Ayaori, N. Ohrui et al., "Statin inhibits hypoxia-induced endothelin-1 via accelerated degradation of HIF- $1 \alpha$ in vascular smooth muscle cells," Cardiovascular Research, vol. 95, no. 2, pp. 251-259, 2012.

[134] H. Malekinejad, M. Mehrabi, M. Khoramjouy, and A. RezaeiGolmisheh, "Antifibrotic effect of atorvastatin on paraquatinduced pulmonary fibrosis: Role of PPAR $\gamma$ receptors," European Journal of Pharmacology, vol. 720, no. 1-3, pp. 294-302, 2013.

[135] N. Alizadeh-Tabrizi, H. Malekinejad, S. Varasteh, and H. Cheraghi, "Atorvastatin protected from paraquat-induced cytotoxicity in alveolar macrophages _via_down-regulation of TLR-4," Environmental Toxicology and Pharmacology, vol. 49, pp. 8-13, 2017.
[136] S. Choudhury, K. Kandasamy, B. S. Maruti et al., "Atorvastatin along with imipenem attenuates acute lung injury in sepsis through decrease in inflammatory mediators and bacterial load," European Journal of Pharmacology, vol. 765, pp. 447-456, 2015.

[137] X. Y. Han, H. Liu, C. H. Liu et al., "Synthesis of the optical isomers of a new anticholinergic drug, penehyclidine hydrochloride (8018)," Bioorganic \& Medicinal Chemistry Letters, vol. 15, no. 8, pp. 1979-1982, 2005.

[138] J. Zhan, F. Xiao, J. J. Li et al., "Penehyclidine hydrochloride decreases pulmonary microvascular permeability by upregulating beta arrestins in a murine cecal ligation and puncture model," The Journal of Surgical Research, vol. 193, no. 1, pp. 391-398, 2015.

[139] X. J. Wu, H. M. Liu, X. M. Song et al., "Penehyclidine hydrochloride inhibits TLR4 signaling and inflammation, and attenuates blunt chest trauma and hemorrhagic shockinduced acute lung injury in rats," Molecular Medicine Reports, vol. 17, no. 5, pp. 6327-6336, 2018.

[140] Z. Liu, Y. Li, L. Yu, Y. Chang, and J. Yu, "Penehyclidine hydrochloride inhibits renal ischemia/reperfusion-induced acute lung injury by activating the Nrf2 pathway," Aging, vol. 12 , no. 13 , pp. 13400-13421, 2020.

[141] G. M. Wu, M. Mou, L. Q. Mo et al., "Penehyclidine hydrochloride postconditioning on lipopolysaccharide-induced acute lung injury by inhibition of inflammatory factors in a rodent model," The Journal of Surgical Research, vol. 195, no. 1, pp. 219-227, 2015.

[142] J. Cui, C. S. Li, X. H. He, and Y. G. Song, "Protective effects of penehyclidine hydrochloride on acute lung injury caused by severe dichlorvos poisoning in swine," Chinese Medical Journal, vol. 126, no. 24, pp. 4764-4770, 2013.

[143] R. Zhu, Y. Zhao, X. Li et al., "Effects of penehyclidine hydrochloride on severe acute pancreatitis-associated acute lung injury in rats," Biomedicine \& Pharmacotherapy, vol. 97, pp. 1689-1693, 2018.

[144] G. Li, L. Zhou, C. Zhang et al., "Insulin-like growth factor 1 regulates acute inflammatory lung injury mediated by influenza virus infection," Frontiers in Microbiology, vol. 10, article 2541, 2019.

[145] F. Tong, X. Tang, X. Li, W. Xia, and D. Liu, "The effect of insulin-loaded linear poly(ethylene glycol)-brush-like poly(l-lysine) block copolymer on renal ischemia/reperfusion-induced lung injury through downregulating hypoxiainducible factor," International Journal of Nanomedicine, vol. 11, pp. 1717-1730, 2016.

[146] L. Ding, B. Zhang, J. Li, L. Yang, and Z. Wang, "Beneficial effect of resveratrol on $\alpha$-naphthyl isothiocyanate-induced cholestasis via regulation of the FXR pathway," Molecular Medicine Reports, vol. 17, no. 1, pp. 1863-1872, 2018.

[147] J. H. Ko, G. Sethi, J. Y. Um et al., "The role of resveratrol in cancer therapy," International Journal of Molecular Sciences, vol. 18, no. 12, article 2589, 2017.

[148] L. Malaguarnera, "Influence of resveratrol on the immune response," Nutrients, vol. 11, no. 5, p. 946, 2019.

[149] C. Sawda, C. Moussa, and R. S. Turner, "Resveratrol for Alzheimer's disease," Annals of the New York Academy of Sciences, vol. 1403, no. 1, pp. 142-149, 2017.

[150] N. Xia, A. Daiber, U. Forstermann, and H. Li, "Antioxidant effects of resveratrol in the cardiovascular system," British Journal of Pharmacology, vol. 174, no. 12, pp. 1633-1646, 2017. 
[151] K. Cheng, Z. Song, S. Li et al., "Effects of resveratrol on intestinal oxidative status and inflammation in heat-stressed rats," Journal of Thermal Biology, vol. 85, article 102415, 2019.

[152] L. Liang, X. Liu, Q. Wang, S. Cheng, S. Zhang, and M. Zhang, "Pharmacokinetics, tissue distribution and excretion study of resveratrol and its prodrug 3,5,4' ${ }^{\prime}$-tri- $O$-acetylresveratrol in rats," Phytomedicine, vol. 20, no. 6, pp. 558-563, 2013.

[153] W. Chen and G. Chen, "Danshen (Salvia miltiorrhiza Bunge): a prospective healing sage for cardiovascular diseases," Current Pharmaceutical Design, vol. 23, no. 34, pp. 5125-5135, 2017.

[154] X. Zhang, T. Wang, Y. Yang et al., “Tanshinone IIA attenuates acetaminophen-induced hepatotoxicity through HOTAIR- Nrf2-MRP2/4 signaling pathway," Biomedicine \& Pharmacotherapy, vol. 130, article 110547, 2020.

[155] H. Jin, X. Peng, Y. He, J. B. Ruganzu, and W. Yang, “Tanshinone IIA suppresses lipopolysaccharide-induced neuroinflammatory responses through NF- $\kappa \mathrm{B} / \mathrm{MAPKs}$ signaling pathways in human U87 astrocytoma cells," Brain Research Bulletin, vol. 164, pp. 136-145, 2020.

[156] M. Xu, F. Cao, L. Liu et al., “Tanshinone IIA-induced attenuation of lung injury in endotoxemic mice is associated with reduction of hypoxia-inducible factor $1 \alpha$ expression," American Journal of Respiratory Cell and Molecular Biology, vol. 45, no. 5, pp. 1028-1035, 2011.

[157] N. Oh, K. Kim, S. Jin Kim et al., "A designed angiopoietin-1 variant, dimeric CMP-Ang1 activates Tie2 and stimulates angiogenesis and vascular stabilization in N-glycan dependent manner," Scientific Reports, vol. 5, no. 1, article 15291, 2015.

[158] I. Kim, S. O. Moon, S. K. Park, S. W. Chae, and G. Y. Koh, "Angiopoietin-1 reduces VEGF-stimulated leukocyte adhesion to endothelial cells by reducing ICAM-1, VCAM-1, and E-selectin expression," Circulation Research, vol. 89, no. 6, pp. 477-479, 2001.

[159] C. H. Cho, R. A. Kammerer, H. J. Lee et al., "COMP-Ang1: a designed angiopoietin-1 variant with nonleaky angiogenic activity," Proceedings of the National Academy of Sciences of the United States of America, vol. 101, no. 15, pp. 55475552, 2004.

[160] M. Kuroki, E. E. Voest, S. Amano et al., "Reactive oxygen intermediates increase vascular endothelial growth factor expression in vitro and in vivo," The Journal of Clinical Investigation, vol. 98, no. 7, pp. 1667-1675, 1996.

[161] P. A. J. Henricks and F. P. Nijkamp, "Reactive oxygen species as mediators in asthma," Pulmonary Pharmacology \& Therapeutics, vol. 14, no. 6, pp. 409-421, 2001.

[162] S. R. Kim, K. S. Lee, S. J. Park et al., "Angiopoietin-1 variant, COMP-Ang1 attenuates hydrogen peroxide-induced acute lung injury," Experimental \& Molecular Medicine, vol. 40, no. 3, pp. 320-331, 2008.

[163] F. Deng, S. Wang, S. Cai et al., "Inhibition of caveolae contributes to propofol preconditioning-suppressed microvesicles release and cell injury by hypoxia-reoxygenation," Oxidative Medicine and Cellular Longevity, vol. 2017, Article ID 3542149, 13 pages, 2017.

[164] P. E. Marik, "Propofol: an immunomodulating agent," Pharmacotherapy, vol. 25, 5 Part 2, pp. 28S-33S, 2005.

[165] S. Tan, H. Liu, Y. Wang, and S. Zhu, "The molecular mechanisms associated with the effects of propofol in a rat model of pain due to inflammation following injection with complete
Freund's adjuvant," Medical Science Monitor, vol. 25, pp. 10190-10197, 2019.

[166] L. Zhang, J. Wang, J. Liang et al., "Propofol prevents human umbilical vein endothelial cell injury from Ang II-induced apoptosis by activating the ACE2-(1-7)-Mas axis and eNOS phosphorylation," PLoS One, vol. 13, no. 7, article e0199373, 2018.

[167] W. Yao, G. Luo, G. Zhu et al., "Propofol activation of the Nrf2 pathway is associated with amelioration of acute lung injury in a rat liver transplantation model," Oxidative Medicine and Cellular Longevity, vol. 2014, Article ID 258567, 9 pages, 2014.

[168] C. H. Chu, L. D. David, Y. H. Hsu, K. C. Lee, and H. I. Chen, "Propofol exerts protective effects on the acute lung injury induced by endotoxin in rats," Pulmonary Pharmacology \& Therapeutics, vol. 20, no. 5, pp. 503-512, 2007.

[169] C. H. Yeh, W. Cho, E. C. So et al., "Propofol inhibits lipopolysaccharide-induced lung epithelial cell injury by reducing hypoxia-inducible factor- $1 \alpha$ expression," British Journal of Anaesthesia, vol. 106, no. 4, pp. 590-599, 2011. 